\title{
Tratamento de lesões condrais no joelho com condrócitos autólogos embebidos em arcabouço de fibrina. Avaliação clínica e funcional*
}

\section{Treatment of Chondral Knee Lesions with Autologous Chondrocytes Embedded in a Fibrin Scaffold. Clinical and Functional Assessment}

\author{
${ }^{1}$ Departamento de Cirurgia Ortopédica, Hospital Jose E Gonzalez, \\ Universidad Autonóma de Nuevo Leon, Monterrey, México \\ 2 Departamento de Bioquímica, Universidad Autonóma de Nuevo \\ Leon, Monterrey, México \\ ${ }^{3}$ Facultad de Medicina, Universidade San Pablo CEU, IMMA, Boadilla \\ del Monte, Madri, Espanha
}

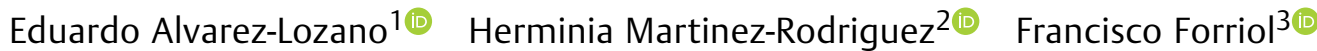

Rev Bras Ortop 2021;56(4):470-477.

\author{
Endereço para correspondência Francisco Forriol, MD, PhD, \\ Universidade San Pablo CEU, Campus Montepríncipe, Boadilla del \\ Monte, Madrid, 28668, Espanha (e-mail: fforriol@gmail.com).
}

\begin{abstract}
Resumo
Palavras-chave

- cartilagem

- joelho

- osso escafoide

- condrócitos

- fibrina

Objetivo O objetivo do nosso estudo é analisar os resultados clínicos e funcionais do tratamento de lesões nas articulações do joelho com condrócitos autólogos embebidos em arcabouço de fibrina.

Métodos $\mathrm{O}$ estudo foi realizado com 56 pacientes (36 homens e 20 mulheres) com idade média de 36 anos; 6 indivíduos eram atletas profissionais. Os pacientes apresentavam lesões únicas, condrais ou osteocondrais (43 condrais, nove osteocondrais, 2 casos de osteocondrite dissecante e duas fraturas osteocondrais) no joelho, $\operatorname{com} 2$ a $10 \mathrm{~cm}^{2}$ de tamanho e $\leq 10 \mathrm{~mm}$ de profundidade, sem sinais de osteoartrite. As lesões estavam localizadas na patela (8), no côndilo femoral medial (40), no côndilo femoral lateral (7) e na tróclea (1). O período médio de acompanhamento foi de 3 anos (faixa de 1-6 anos). A evolução clínica foi avaliada pelos escores de Cincinnati e Knee Injury and Osteoarthritis Outcome (KOOS), 6 e 12 meses após a cirurgia. $\mathrm{O}$ teste $\mathrm{t}$ de Student pareado foi utilizado para comparação dos achados pré e pós-operatórios.

Resultados Os pacientes retomaram suas atividades diárias 6 meses após o implante. Os escores avaliados demonstraram a melhora em comparação ao estado pré-cirúrgico $(p<0,05)$. Além disso, os pacientes conseguiram realizar suas atividades esportivas com mais facilidade do que antes da cirurgia $(p<0,05)$.

Conclusão A cultura de condrócitos em fibrina pode proporcionar um microambiente favorável para a síntese de matriz extracelular e melhorar a condição clínica e a atividade dos pacientes 1 ano após a cirurgia
\end{abstract}

\footnotetext{
Estudo desenvolvido na Facultad de Medicina, Universidade San Pablo CEU, IMMA, Boadilla del Monte, Madri, Espanha.
}

recebido

05 de Janeiro de 2020

aceito

06 de Julho de 2020

Publicado on-line

Outubro 29, 2020
DOI https://doi.org/ $10.1055 / \mathrm{s}-0040-1716764$ ISSN 0102-3616.
(C) 2020. Sociedade Brasileira de Ortopedia e Traumatologia. All rights reserved.

This is an open access article published by Thieme under the terms of the Creative Commons Attribution-NonDerivative-NonCommercial-License, permitting copying and reproduction so long as the original work is given appropriate credit. Contents may not be used for commercial purposes, or adapted, remixed, transformed or built upon. (https://creativecommons.org/ licenses/by-nc-nd/4.0/)

Thieme Revinter Publicações Ltda., Rua do Matoso 170, Rio de Janeiro, RJ, CEP 20270-135, Brazil 
Abstract
Keywords
- cartilage
- knee
- scaphoid bone
- chondrocytes
- fibrin

Objective The aim of our study is to analyze the clinical and functional results obtained using autologous chondrocytes embedded in a fibrin scaffold in knee joint injuries.

Methods We included 56 patients, 36 men and 20 women, with a mean age 36 years. Six of the patients were professional athletes, with single knee injuries that were either chondral or osteochondral ( 43 chondral, 9 osteochondral, 2 cases of osteochondritis dissecans and 2 osteochondral fractures), 2 to $10 \mathrm{~cm}^{2}$ in size and $\leq 10 \mathrm{~mm}$ deep, with no signs of osteoarthritis. The location of the injury was in the patella (8), the medial femoral condyle (40) and lateral femoral condyle (7) and one in the trochlea. The mean follow-up was 3 (range: 1-6) years. The clinical course was assessed using the Cincinnati and Knee Injury and Osteoarthritis Outcome (KOOS) scores, 6 and 12 months after surgery. The paired Student t-test was used to compare pre-and postoperative results.

Results Six months after the implant, patients resumed their everyday activities. On the assessment scores, their condition was improving in comparison with their presurgical state $(p<0.05)$. They were also able to carry out their sporting activities more easily than prior to surgery $(p<0.05)$.

Conclusion The seeding of chondrocytes in fibrin may provide a favorable microenvironment for the synthesis of extracellular matrix and improved the clinical condition and activity of the patients 1 year after surgery.

\section{Introdução}

Lesões condrais e osteocondrais provocam degeneração articular, o que pode exigir a colocação de uma prótese. ${ }^{1}$ A cartilagem é um tecido de baixa densidade celular cujo reparo ou regeneração precisa de suporte., ${ }^{2,3}$ Para isso, técnicas cirúrgicas baseadas em métodos regenerativos utilizam bioengenharia para desenvolvimento de um novo tecido de cartilagem hialina (implante autólogo de condrócitos [IAC], células-tronco mesenquimatosas [CTMs] ou condrócitos em diferentes arcabouços [CDAs]). ${ }^{2}$ Essas técnicas podem ser realizadas por meio de cirurgia aberta, miniartrotomia ou artroscopia.

O IAC foi desenvolvido a partir do implante de células cultivadas na própria lesão, como uma suspensão celular, ${ }^{4}$ para inclusão em arcabouços biodegradáveis ${ }^{5,6}$ que permitem a síntese de matriz extracelular e a diferenciação celular. Embora o número de células seja homogêneo entre as publicações, o tipo de matriz utilizada é bastante variável.

Outro aspecto a considerar nesse tipo de tratamento é que, durante o crescimento celular, em certas condições, a morfologia e o fenótipo celular podem ser alterados, com expressão de fatores de transcrição, como o gene Sox9, a produção de col2 ou a síntese de col1, col3 ou col10 e a geração de uma matriz extracelular de más condições biomecânicas ${ }^{7}$ e sua diferenciação em um tecido que também tem baixa qualidade para desempenhar a função da cartilagem hialina. ${ }^{8}$ A cultura dos condrócitos em um ambiente condrotrópico, porém, pode levar a sua diferenciação para desenvolvimento de tecido cartilaginoso hialino. ${ }^{9}$

As técnicas regenerativas têm altos custos econômicos e alta morbidade; além disso, nem sempre estão associadas a melhores resultados em longo prazo. ${ }^{10,11}$ O objetivo do nosso estudo é analisar os resultados clínicos em pacientes com lesões condrais tratadas com condrócitos autólogos cultivados em um arcabouço de fibrina.

\section{Material e Metodologia}

Estudo prospectivo com 56 pacientes, 36 homens e 20 mulheres, operados entre abril de 2014 e outubro de 2017 por apresentarem dor, bloqueio articular e limitações funcionais do joelho. A média de idade dos pacientes foi de 36 anos (desviopadrão [DP]: 13; faixa: 16-64). O período médio de acompanhamento foi de 27 meses (DP: 16; faixa: 12-72). Trinta e duas lesões eram no joelho esquerdo e 24 , no joelho direito. Quanto à localização, havia 43 lesões condrais, 9 lesões osteocondrais, 2 casos de osteocondrite dissecante e 2 traumatismos osteocondrais. Oito lesões afetavam a patela, 40 estavam no côndilo femoral medial, 7 no côndilo femoral lateral e, por fim, havia 1 caso na tróclea. Quarenta e três dos pacientes eram praticantes de atividades esportivas e 6 eram atletas profissionais.

Os critérios de inclusão foram pacientes com idade entre $16 \mathrm{e}$ 65 anos, sem sinais de osteoartrite ou doença reumática, sendo operados pela primeira vez com lesões únicas, condrais ou osteocondrais, com 2 a $10 \mathrm{~cm}^{2}$ de tamanho e lesão óssea com $\leq 10 \mathrm{~mm}$ de profundidade. Os critérios de exclusão foram a presença de osteoartrite de grau II ou superior na escala de Kellgren-Lawrence, obesidade mórbida (índice de massa corporal [IMC] $>40$ ) e deformidade em valgo ou varo superior a $10^{\circ}$.

A cirurgia foi realizada de 1 a 6 anos após o aparecimento dos sintomas, mas, na maioria dos casos, esse período foi de 2 a 4 anos. Em cinco ocasiões, a lesão da cartilagem foi associada à 
ruptura do menisco ou do ligamento cruzado anterior, que foi reparada na mesma cirurgia. 0 eixo mecânico dos membros inferiores foi examinado para detecção de deformação em valgo ou varo. Osteotomias corretivas não foram realizadas.

Os pacientes foram avaliados pelos escores de joelho de Cincinnati e Knee Injury and Osteoarthritis Outcome (KOOS) antes e 6 e 12 meses após a cirurgia. A amplitude de movimento e a presença de crepitação foram medidas e, em cada avaliação, radiografias em incidência anteroposterior e sagital, com o paciente em pé, e ressonância magnética (RM) do joelho foram obtidas. A amplitude de movimento antes e depois da cirurgia foi avaliada separadamente pelas duas escalas.

\section{Procedimento de Obtenção de Cartilagem}

O espécime de cartilagem foi obtido da fossa intercondilar por procedimento artroscópico, com uso do sistema de transplante autólogo osteocondral OATS (Artrex, Karisfeld, Alemanha) de $8 \mathrm{~mm}$ de diâmetro. A cartilagem extraída foi armazenada em soro fisiológico suplementado com $0,05 \mathrm{mg}$ de gentamicina. Em nosso laboratório de engenharia de tecidos, expandimos e mantivemos os condrócitos in vitro de acordo com os procedimentos do banco de ossos e tecidos.

\section{Cultura de Condrócitos}

A cultura de condrócitos foi realizada de acordo com uma versão modificada da técnica desenvolvida por Visna et al. ${ }^{6} \mathrm{~A}$ cartilagem articular foi seccionada em pequenos cubos de $1 \mathrm{a}$ $3 \mathrm{~mm}^{3}$ sob fluxo laminar de classe II. Os fragmentos de cartilagem foram tratados com tripsina (GIBCO-BRL Life Technologies, Grand Island, NY, Estados Unidos) e, para digestão da matriz condral, com colagenase tipo II (GIBCOBRL Life Technologies). Os condrócitos obtidos foram inocu- lados em frascos de cultura de $75 \mathrm{~cm}^{2}$ (NUNC'M Creek Drive, Rochester, NY, Estados Unidos) para crescimento in vitro com meio Opti-MEM (GIBCO-BRL Life Technologies), suplementado com soro humano autólogo (SHA) a $10 \%$ e gentamicina. As culturas foram mantidas em uma atmosfera controlada com $5 \%$ de $\mathrm{CO}_{2}$ e umidade relativa de $100 \%$. Quando as culturas em monocamada atingiram 70 a $80 \%$ de confluência, as células foram destacadas e incubadas em tripsina-EDTA (GIBCO-BRL Life Technologies).

Uma cola à base de fibrina foi utilizada para semear os condrócitos em um arcabouço tridimensional. Seguimos as instruções do fabricante e, antes de misturar o fibrinogênio e a trombina fornecidos no recipiente, adicionamos os condrócitos para que ficassem em suspensão de fibrina. Ao estimar a confluência de $80 \%$, as células foram suspensas com tripsina-EDTA a 0,25\%, contadas em uma câmara de Neubauer com trypan blue e subcultivadas em três frações para estimular a propagação celular e permitir o estabelecimento de novas culturas até a obtenção de 15 milhões de células. Testes microbiológicos foram realizados para assegurar a ausência de contaminação das culturas. Esse número de condrócitos foi obtido em 26 dias e em frascos de cultura de $15 \times 75 \mathrm{~cm}^{2}$. A seguir, as células foram semeadas no arcabouço tridimensional de fibrina, que foi colocado em um molde e mantido por 5 minutos.

\section{Técnica Cirúrgica (-Fig. 1)}

A cirurgia foi realizada no dia seguinte à semeadura das células. Uma artrotomia foi realizada e a área de lesão foi exposta. Em seguida, os fragmentos osteocondrais soltos foram removidos e o tecido cicatricial no leito da lesão foi submetido à curetagem. Um milímetro das bordas da cartilagem articular ao redor da lesão foi removido e pequenas
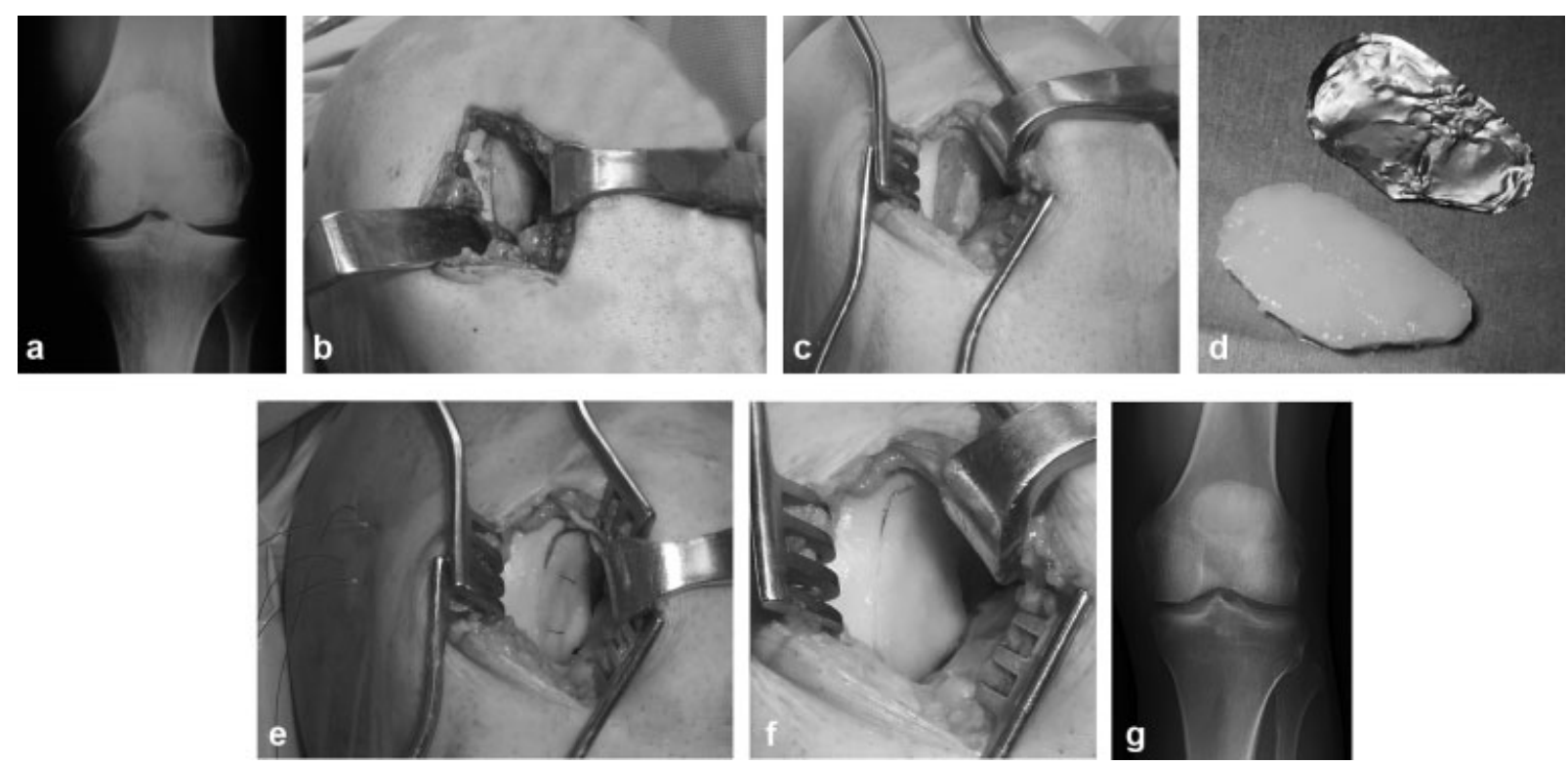

Fig. 1 (a) Radiografia pré-operatória, (b) Uma artrotomia foi realizada e a área lesada foi exposta. (c) Os fragmentos osteocondrais soltos foram removidos e o tecido cicatricial no leito da lesão foi submetido à curetagem; pequenas perfurações foram feitas na placa óssea subcondral, sem removê-la, para que a cola biológica facilitasse a ancoragem do implante ósseo. (d) Gabarito de alumínio para construção do molde com a mesma morfologia da lesão; (e) Suturas reabsorvíveis. (f) Após a colocação do implante, as suturas transosóseas foram removidas e uma camada de cola de fibrina foi colocada na superfície articular do enxerto; (g) Radiografia de controle obtida 12 meses após o procedimento. 
perfurações foram feitas na placa óssea subcondral, sem removê-la, para que a cola biológica facilitasse a ancoragem do implante ósseo.

Um gabarito de alumínio foi utilizado para construção de um molde com a mesma morfologia da lesão e o tamanho e a forma do implante foram projetados de forma a assegurar o contato das bordas com o defeito ósseo receptor. Âncoras cirúrgicas de titânio de 2,4 mm (MiniFasTak ${ }^{\circledR}$, Arthrex, Naples, Flo, U.S.A) foram introduzidas nas bordas da lesão, com mudança das suturas para suturas PDS II (polidioxanona) de fios reabsorvíveis (Ethicon, Inc., Sommerville, NJ, USA). Ao inserir as âncoras nas bordas do defeito, o fio de sutura atravessou o implante em si (Condrograft ${ }^{\circledR}$, Banco de Huesos, UANL, Monterrey Mexico) que está em contato com o osso subcondral e, a seguir, atravessou novamente o implante por seu aspecto superior, assegurando sua proximidade com o outro lado do orifício. Um túnel transósseo foi preparado em direção ao lado livre do côndilo. Por esse túnel, o fio usado para sutura do implante foi introduzido. Após o posicionamento das âncoras e a inserção do fio pelo túnel transósseo, as suturas foram identificadas e os nós foram dados sem exercer pressão até o término da próxima etapa de fixação.

Para integração total do enxerto de fibrina, a cola biológica de fibrina Tissucol (Baxter Biosciences, Viena, Áustria) foi utilizada para formação de um coágulo estável, sem afetar as células semeadas, e incentivar sua integração ao tecido cartilaginoso saudável e a migração celular para o enxerto.

A cola Tissucol foi aplicada em uma camada sobre o defeito e, imediatamente depois, o enxerto foi inserido e mantido em posição usando as suturas transósseas; o enxerto foi abaixado e colocado manualmente por tração dessas suturas para que suas bordas entrassem em contato com os lados do defeito. Após a colocação de Condrograft em sua posição definitiva no interior da lesão, as suturas transósseas foram removidas, sem força excessiva, na direção do aspecto livre do côndilo femoral. Por fim, uma camada de cola foi aplicada na superfície articular do enxerto e no ponto de união à cartilagem normal.

Após o fechamento da ferida por planos, a articulação do joelho foi colocada em extensão por 8 horas para permitir a secagem completa de Tissucol.

\section{Cuidado pós-operatório}

A movimentação passiva foi permitida 8 horas após a cirurgia e movimentação ativa, em 48 horas. A deambulação parcial foi permitida depois de 10 dias, com muletas e carga progressiva. Após 6 semanas, permitimos a locomoção plantí- grada com $75 \%$ do peso corporal. O protocolo de fisioterapia foi concluído 18 semanas após a cirurgia, quando as muletas foram removidas e o suporte de carga passou a ser total.

\section{Aquisição de dados de ressonância magnética}

As imagens de RM foram adquiridas com equipamento GE de 1,5 Tesla (General Electric Healthcare, Milwaukee, WI, Estados Unidos). Três sequências clinicamente apropriadas (FS FGRE tridimensional [3D], FSE [dual echo spin echo] bidimensional [2D] e FSE [fast spin echo] 2D) foram adquiridas de cada participante do estudo. Todas as imagens foram revistas por um radiologista experiente para confirmação da ausência de patologia.

Duas sequências de imagens foram usadas. Imagens 2D de FSE com eco duplo foram adquiridas para cálculo, em pixels, da densidade de prótons (PD) em mapas de relaxamento T2. As imagens 3D de FS FGRE foram segmentadas com um método semiautomatizado baseado em atlas (QMetrics, Inc., Rochester, NY, Estados Unidos). As imagens foram segmentadas, como já descrito, em sub-regiões ósseas e cartilaginosas usando oito atlas. Essa abordagem produziu oito segmentações separadas que foram comparadas voxel por voxel para criação de um mapa de segmentação. As segmentações de cartilagem foram obtidas das regiões medial e lateral de sustentação do peso do fêmur e da cartilagem medial e lateral da tíbia. Mapas de segmentação da cartilagem foram utilizados para determinação do volume $\left(\mathrm{mm}^{3}\right) \mathrm{e}$ da espessura média ( $\mathrm{mm}$ ) de cada região de interesse. Esse método produziu valores de precisão em teste-reteste da espessura da cartilagem femoral de $0,014 \mathrm{~mm}(0,6 \%)$ em imagens obtidas à ressonância magnética de $1,5 \mathrm{~T}^{12}$ (- Fig. 2).

\section{Análise estatística}

Uma análise estatística descritiva foi realizada, com uso do teste $\mathrm{t}$ de Student pareado para comparação dos escores antes e depois da cirurgia.

\section{Resultados}

Antes da cirurgia, a maioria dos pacientes relatava dor e inflamação, o que os impedia de realizar suas atividades normais

No período pós-operatório, os pacientes realizavam atividades diárias normais cotidianas e de trabalho, além de praticarem exercícios leves; um terço deles achava que o joelho
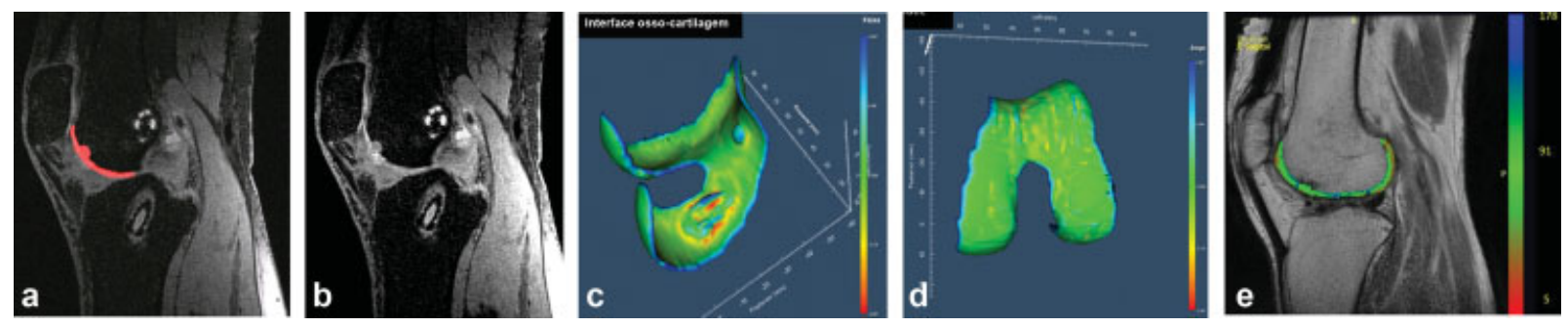

Fig. 2 (a,b) Incidência sagital pré-operatória da cartilagem do côndilo femoral em sequência FS FGRE tridimensional (3D); (c, d) Renderização 3D da curvatura da superfície. A interface da cartilagem óssea mostra a extensão da lesão condral. A superfície articular mostra a cartilagem íntegra. (e) Incidência sagital da cartilagem em mapeamento ponderado em T2 estimado a partir de sequência FSE (dual echo spin echo) bidimensional. A ponderação em T2 da cartilagem normal varia de 20 a 100 milissegundos. 
Tabela 1 Evolução dos escores de Cincinnati e Knee Injury and Osteoarthritis Outcome (KOOS) durante o acompanhamento

\begin{tabular}{|l|l|l|}
\hline $\begin{array}{l}\text { Acompanhamento } \\
\text { (meses) } \\
\text { Pós-operatório }\end{array}$ & $\begin{array}{l}\text { Cincinnati } \\
\text { X (Desvio } \\
\text { padrão) } \\
\text { faixa }\end{array}$ & $\begin{array}{l}\text { KOOS } \\
\text { X (Desvio } \\
\text { padrão) } \\
\text { faixa }\end{array}$ \\
\hline Pré-operatório & $53,2(16,96)$ & $\begin{array}{l}56,04(15,29) \\
22,6-76,19\end{array}$ \\
\hline$<6$ & $10-79$ & $86,57(11,46)$ \\
& $88,69(13,03)$ & $52,38-97,6$ \\
\hline $7-14$ & $42-100$ & $87,47(16,17)$ \\
& $85(16,54)$ & $40,48-98,8$ \\
\hline $15-24$ & $55-100$ & $89,85(8,47)$ \\
& $82,38(16,16)$ & $66,07-98,8$ \\
\hline
\end{tabular}

estava normal e que podia realizar exercícios e tarefas mais difíceis. Houve uma melhora na percepção dos sintomas após a cirurgia, embora a diferença não tenha sido significativa. 0 escore geral dos pacientes nas escalas de Cincinnati e KOOS (-Tabela 1) melhorou ao longo do tempo, mas mais diferenças não foram detectadas após os primeiros 6 meses ( - Fig. 3a). A mobilidade variou após o tratamento, sendo normal após 6 meses após a cirurgia.

A avaliação funcional das atividades cotidianas antes da cirurgia mostrou que $50 \%$ dos pacientes conseguiam andar menos de um quarteirão e apresentavam limitações ao subir escadas ou agachar. Seis meses depois da cirurgia, 75\% dos pacientes conseguiam realizar suas atividades diárias normalmente. Uma melhora clínica ao andar, subir escadas, sentar e ajoelhar foi observada 6 meses após a cirurgia $(p<0,05)$ (-Tabela 2) (-Tabela 3). Quanto às atividades esportivas, houve uma clara melhora na capacidade dos pacientes após a cirurgia em comparação aos achados préoperatórios $(p<0,05)$ (-Fig. 3b).

Não houve diferença nos escores clínicos entre mulheres e homens durante o acompanhamento (-Tabela 2) em qualquer uma das escalas. Os resultados das lesões osteocondrais foram melhores em comparação às lesões condrais no último exame, aos 24 meses (-Tabela 2) (-Tabela 3). Esses melhores resultados das lesões osteocondrais podem se dever à maior esclerose subcondral das lesões condrais, causando

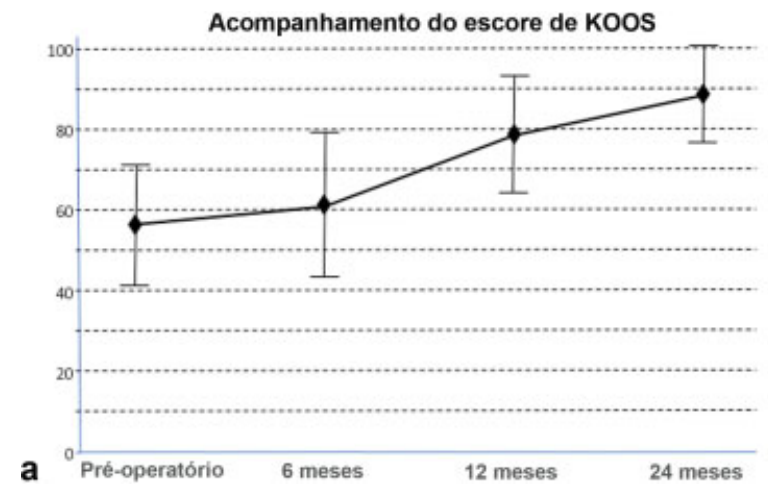

mais deformidades no sítio de implante. Além disso, as lesões osteocondrais recebem células migrantes da medula óssea, garantindo uma fixação mais completa da matriz do bioimplante no osso.

Dos 43 pacientes que participavam de atividades esportivas, 15 (34,88\%) continuaram a praticá-las. Dos seis atletas profissionais, cinco continuaram e um teve que desistir do esporte.

Seis complicações $(10,71 \%)$ foram detectadas, metade delas relacionadas à artrotomia. Houve três casos de artrofibrose, sendo um acompanhado por uma síndrome complexa de dor regional. A artrofibrose foi tratada com artrólise artroscópica e mobilização sob anestesia. O paciente com síndrome complexa de dor regional passou por uma interconsulta com o departamento de medicina da dor, onde foi tratado, sem melhora. 0 paciente acabou por receber uma prótese unicondilar de joelho. Outros três pacientes com enxerto no côndilo medial ainda apresentavam dor e, em um segundo momento, dois deles apresentavam delaminação total do enxerto e o outro sofreu perda completa do implante. Como a ferida estava aberta, os três casos receberam um aloenxerto osteocondral fresco do banco ósseo.

No escore de satisfação do paciente, 16 (28,6\%) indivíduos estavam muito satisfeitos, 30 (53,6\%) estavam satisfeitos e recomendariam a cirurgia, $8(14,3 \%)$ estavam insatisfeitos e 2 $(3,5 \%)$ ficaram decepcionados. Esses dois últimos pacientes foram os que apresentaram as complicações mais graves: um caso de artrofibrose e outro de delaminação do enxerto.

\section{Discussão}

A técnica de CDAs é bem documentada no reparo de lesões condrais e é uma segunda indicação, em caso de insucesso de outros tratamentos, em lesões com 2 a $10 \mathrm{~cm}^{2}$ em pernas alinhadas de pacientes jovens e ativos.

Os algoritmos mais utilizados são baseados na localização, tamanho e profundidade da lesão e no nível de atividade do paciente. ${ }^{13,14} \mathrm{O}$ tamanho da lesão e o nível de atividade do paciente são os fatores mais importantes na determinação do tratamento correto. Os critérios que garantem bons resultados são os seguintes: os pacientes devem ser jovens, não obesos, não fumantes, não terem sidon submetidos a cirurgias prévias na área e devem apresentar defeitos no côndilo femoral

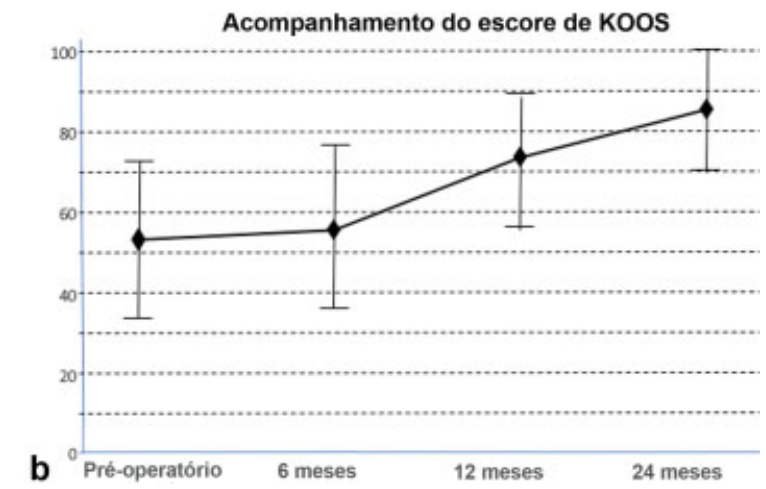

Fig. 3 (a) O escore de KOOS e (b) o escore de Cincinnati melhoraram com o passar do tempo, embora não haja mais diferenças depois os primeiros seis meses. 
Tabela 2 Evolução do escore Knee Injury and Osteoarthritis Outcome (KOOS) na população geral e conforme o sexo (feminino e masculino) e o tipo de lesão (condral ou osteocondral)

\begin{tabular}{|l|l|l|l|l|}
\hline & $\begin{array}{l}\text { Pré-operatório } \\
\text { X (desvio padrão) } \\
\text { faixa }\end{array}$ & $\begin{array}{l}\text { 6 meses } \\
\text { X (desvio padrão) } \\
\text { faixa }\end{array}$ & $\begin{array}{l}12 \text { meses } \\
\text { X (desvio padrão) } \\
\text { faixa }\end{array}$ & $\begin{array}{l}24 \text { meses } \\
\text { X (desvio padrão) } \\
\text { faixa }\end{array}$ \\
\hline Geral & $\begin{array}{l}6,04(15,29) \\
22,6-76,19\end{array}$ & $\begin{array}{l}62,52(18,62) \\
30,3-94,59\end{array}$ & $\begin{array}{l}78,63(14,43) \\
35,12-96,43\end{array}$ & $\begin{array}{l}88,11(12,23) \\
40,48-98,8\end{array}$ \\
\hline Sexo feminino & $58,27(15,29)$ & $\begin{array}{l}67,99(18,09) \\
36,9-92,26\end{array}$ & $\begin{array}{l}78,78(15,27) \\
39,88-95,27\end{array}$ & $\begin{array}{l}87,33(17,13) \\
98,8-50,59\end{array}$ \\
\hline Sexo masculino & $25-75,59$ & $59,48(18,46)$ & $78,55(14,17)$ & $\begin{array}{l}88,54(12,32) \\
40,48-98,8\end{array}$ \\
\hline Lesão de cartilagem & $30,3-94,59$ & $35,12-96,43$ & \\
\hline Condral & $22,6-76,19$ & & $\begin{array}{l}78,89(13,12) \\
39,88-96,43\end{array}$ & $\begin{array}{l}88,73(9,99) \\
50,6-98,8\end{array}$ \\
\hline Osteocondral & $55,93(14,36)$ & $63,51(17,19)$ & $84,22(11,67)$ & $\begin{array}{l}93,36(4,39) \\
85,71-98,8\end{array}$ \\
\hline
\end{tabular}

Tabela 3 Evolução do escore de Cincinnati na população geral e conforme o sexo (feminino e masculino) e o tipo de lesão (condral ou osteocondral)

\begin{tabular}{|c|c|c|c|c|}
\hline & $\begin{array}{l}\text { Pré-operatório } \\
X \text { (desvio padrão) } \\
\text { faixa }\end{array}$ & $\begin{array}{l}6 \text { meses } \\
X \text { (desvio padrão) } \\
\text { faixa }\end{array}$ & $\begin{array}{l}12 \text { meses } \\
X \text { (desvio padrão) } \\
\text { faixa }\end{array}$ & $\begin{array}{l}24 \text { meses } \\
X \text { (desvio padrão) } \\
\text { faixa }\end{array}$ \\
\hline Geral & $\begin{array}{l}53,2(16,96) \\
10-79\end{array}$ & $\begin{array}{l}56,4(19,30) \\
19-86\end{array}$ & $\begin{array}{l}74,75(16,85) \\
19-93\end{array}$ & $\begin{array}{l}85,07(15,41) \\
42-100\end{array}$ \\
\hline Sexo feminino & $\begin{array}{l}50,9(18,9) \\
10-71\end{array}$ & $\begin{array}{l}59(19,5) \\
19-84\end{array}$ & $\begin{array}{l}71,75(21,4) \\
19-93\end{array}$ & $\begin{array}{l}81,7(18,55) \\
46-100\end{array}$ \\
\hline Sexo masculino & $\begin{array}{l}54,5(15,93) \\
10-79\end{array}$ & $\begin{array}{l}54,94(19,33) \\
19-93\end{array}$ & $\begin{array}{l}76,42(13,75) \\
38-93\end{array}$ & $\begin{array}{l}86,94(13,27) \\
42-100\end{array}$ \\
\hline \multicolumn{5}{|c|}{ Lesão de cartilagem } \\
\hline Condral & $\begin{array}{l}53,35(16,98) \\
10-78\end{array}$ & $\begin{array}{l}56,7(19,36) \\
19-86\end{array}$ & $\begin{array}{l}75,3(16,97) \\
19-93\end{array}$ & $\begin{array}{l}84,93(14,35) \\
46-100\end{array}$ \\
\hline Osteocondral & $\begin{array}{l}53,11(20,25) \\
10-79\end{array}$ & $\begin{array}{l}59(20,1) \\
34-80\end{array}$ & $\begin{array}{l}78,56(10) \\
60-93\end{array}$ & $\begin{array}{l}92,78(5,65) \\
82-100\end{array}$ \\
\hline
\end{tabular}

ou na tróclea sem sinais de degeneração. ${ }^{11}$ A lesão deve ter tamanho inferior a $10 \mathrm{~cm}^{2}$.

Polímeros naturais e arcabouços biodegradáveis sintéticos têm sido utilizados; esses materiais apresentam alta porosidade, grande superfície de contato celular, estrutura estável, formato tridimensional e composição biocompativel. Diferentes tipos de materiais foram propostos, como colágeno $1,{ }^{3}$ ácido hialurônico, ${ }^{5}$ colágeno $3^{15}$ e fibrina. ${ }^{6}$ Os arcabouços de fibrina são formados por dois componentes derivados do plasma sanguíneo (trombina e fibrinogênio) que, juntos, constroem uma matriz específica que oferece bom ambiente para a proliferação de condrócitos. ${ }^{8,16,17}$

As lesões no côndilo femoral medial tenderam a apresentar resultados melhores após 3 anos de acompanhamento do que as do côndilo lateral, mas não as da patela. ${ }^{18}$ Nosso estudo obteve resultados semelhantes aos da literatura. Acreditamos que esses resultados se devam às características de localização das lesões. O côndilo femoral medial é o sítio anatômico com mais carga em comparação a outros locais e, assim, as lesões são um reflexo da carga. As lesões bicondi- lares apresentam artropatia dos dois compartimentos, o que reduz o sucesso da evolução pós-operatória. A articulação femoropatelar não é um sítio de carga direta. A principal função dessa articulação é um mecanismo de polia que facilita os movimentos de flexão e extensão do joelho. Além disso, a patela está intimamente associada ao sulco troclear do fêmur, facilitando o implante de Chondrograft.

A idade é um fator que pode estar relacionado ao processo degenerativo ou ter influência negativa sobre a articulação. ${ }^{19}$ Os melhores resultados são obtidos em pacientes com menos de 30 anos de idade. ${ }^{20,21}$ Embora a maioria dos estudos considere a idade dos pacientes um fator importante para estabelecimento do prognóstico do procedimento, não observamos essa relação. Nossos resultados mostraram que a viabilidade dos condrócitos e as condições dos pacientes, mas não a idade, são os dois principais fatores para o sucesso do tratamento.

O tempo de espera até a cirurgia também influencia o resultado, ${ }^{18,19}$ assim como outros fatores, como a estabilidade da articulação do joelho, a condição de meniscos e ligamentos, 
o peso do paciente (os resultados são melhores quando o IMCé inferior a 30) e o alinhamento do membro inferior.

Nosso estudo utilizou uma modificação da técnica desenvolvida por Visna et al., ${ }^{6}$ com execução de uma ou duas passagens para obtenção de $15 \times 10^{6}$ células em 26 dias e assegurando a preservação da capacidade de rediferenciação dos condrócitos ao serem semeados no arcabouço. Os condrócitos foram cultivados com o soro do próprio paciente para redução do risco de hipersensibilidade aos produtos bovinos e do desenvolvimento de infecção. Nosso objetivo era conseguir a regeneração da superfície articular por meio da regeneração da cartilagem hialina, que se traduz clinicamente em eliminação da dor e da inflamação e melhora funcional.

Em um estudo multicêntrico, Micheli et al. ${ }^{22}$ observaram que $94 \%$ dos enxertos sobreviveram 3 anos após a cirurgia em 50 pacientes com idade média de 36 anos e lesão com tamanho médio de $4,2 \mathrm{~cm}^{2}$. Moseley et al. ${ }^{23}$ confirmaram que, depois de 10 anos, $69 \%$ das cirurgias tiveram resultados melhores, com $17 \%$ de taxa de falha e $12,5 \%$ de casos inalterados.

Na série descrita por Marcacci et al., ${ }^{5}$ com pacientes que receberam CDAs e foram acompanhados por artroscopia, quatro indivíduos apresentavam fibrocartilagem e seis, cartilagem fibro-hialina. A presença de cartilagem hialina foi observada em 11 pacientes. Dos 23 pacientes acompanhados por Roberts et al., ${ }^{24} 7$ tinham fibrocartilagem e apenas 5 indivíduos apresentaram regeneração da cartilagem hialina após um longo período de acompanhamento. Nos demais casos, a lesão era recoberta por cartilagem fibro-hialina. Tins et al. ${ }^{25}$ obtiveram resultados semelhantes: 12 meses após a cirurgia, 25 dos 39 casos apresentavam fibrocartilagem, 10 tinham tecido hialinofibroso e apenas quatro exibiam cartilagem hialina.

Não realizamos biópsias em nossos pacientes, mas sabemos que os condrócitos passam por um processo prolongado de rediferenciação; para evitar isso, recomendamos o armazenamento dessas células em meio viscoso, para que fiquem em suspensão, distantes entre si.

Dois estudos compararam a técnica inicial, o implante autólogo de cultura de condrócitos (IAC), à segunda geração de CDAS e não encontraram diferenças significativas; ${ }^{26,27}$ assim, parece-nos que a técnica original deve estar em desuso por ser mais agressiva e ter evolução mais incerta.

Além disso, a técnica de CDAS tem menos complicações do que a de IAC, embora Bartlett et al. ${ }^{26}$ tenham realizado um estudo prospectivo e randomizado para comparação de CDAs e IAC em 91 pacientes. Os dois grupos apresentaram resultados semelhantes 2 anos após a cirurgia e as duas técnicas provocaram melhora 1 ano após o procedimento. A incidência de hipertrofia foi baixa, de apenas $9 \%(4 / 44)$ no grupo IAC e $6 \%$ (3/47) no grupo CDAs, mas $9 \%$ dos pacientes precisaram de uma segunda cirurgia. $\mathrm{O}$ uso de CDAs também foi associado à observação de áreas de fibrocartilagem, talvez em decorrência da baixa densidade celular e da baixa capacidade proliferativa.

É possível questionar a conveniência de uso dessas técnicas baseadas em biotecnologia, que são mais caras e exigentes do que técnicas mais simples, como microfraturas. Knutsen et al., 21 em um estudo com 40 pacientes, não encontraram diferenças biológicas ou histológicas após 2 anos entre indivíduos tratados com microfraturas ou IAC. Em
5 anos, os resultados foram semelhantes, mas 30\% dos pacientes submetidos às microfraturas apresentavam sinais iniciais de degeneração. ${ }^{10}$ Saris et al. ${ }^{19,28}$ também compararam as microfraturas à técnica de IAC por um período de acompanhamento de 36 meses em 118 pacientes randomizados. O escore geral de KOOS foi semelhante nos dois grupos, embora os resultados relativos à dor e qualidade de vida tenham sido melhores no grupo IAC. A avaliação histológica também foi melhor no grupo $\mathrm{ACl}$ e a reação óssea subcondral foi pior no grupo submetido às microfraturas. Após um acompanhamento maior, o escore de KOOS foi mais positivo no grupo IAC. Da mesma forma, Basad et al., ${ }^{29} \mathrm{em} \mathrm{um}$ estudo randomizado de 2 anos, observaram resultados melhores com CDAs do que microfraturas.

Nossos resultados foram melhores com as lesões osteocondrais do que com as condrais, que apresentam maior esclerose subcondral e, assim, mais deformidades no sítio de implante. Além disso, as lesões osteocondrais recebem células em migração da medula óssea, assegurando a fixação mais completa da matriz de bioimplante no osso.

Quanto às complicações, Vascellari et al. ${ }^{30}$ não as encontram em 30 pacientes acompanhados por 70 meses. Nosso estudo utilizou cola de fibrina para ancoragem adequada das células, ${ }^{6}$ distribuindo-as de maneira homogênea e mantendo-as no interior do enxerto em todos os níveis. Hoje, esta técnica é classificada como de terceira geração e oferece um ambiente condrogênico favorável. Seis meses após o implante, a maioria dos pacientes havia retomado suas atividades cotidianas e podia trabalhar e realizar exercícios normais a moderados. Um terço participava de atividades esportivas e $83 \%$ dos pacientes descreveram o joelho operado como normal. Atualmente, $75 \%$ dos pacientes declaram poder caminhar, subir as escadas e se ajoelhar normalmente, sem nenhum tipo de problema.

Uma limitação do presente estudo é a ausência de dados de biópsia e ressonância magnética. Focamos nos aspectos clínicos da doença e no estado dos pacientes e seu cotidiano. Embora o período de acompanhamento tenha sido longo o suficiente, seria interessante ter pesquisas em prazo ainda mais longo para descobrir quantos desses pacientes precisaram de mais cirurgias ou artroplastias.

A semeadura de condrócitos em um arcabouço de fibrina pode gerar o microambiente favorável para a síntese de matriz extracelular e permite interromper o avanço da doença para restauro da mobilidade articular, redução da dor e retomada mais rápida das atividades diárias do paciente.

\section{Suporte Financeiro}

Não houve suporte financeiro de fontes públicas, comerciais, ou sem fins lucrativos.

\section{Conflito de Interesses}

Os autores declaram que não há conflito de interesses.

\section{Referências}

1 Wakitani S, Kawaguchi A, Tokuhara Y, Takaoka K. Present status of and future direction for articular cartilage repair. J Bone Miner Metab 2008;26(02):115-122 
2 Forriol F. Growth factors in cartilage and meniscus repair. Injury 2009;40(Suppl 3):S12-S16

3 Ochi M, Uchio Y, Kawasaki K, Wakitani S, Iwasa J. Transplantation of cartilage-like tissue made by tissue engineering in the treatment of cartilage defects of the knee. J Bone Joint Surg $\mathrm{Br} 2002 ; 84$ (04):571-578

4 Brittberg M, Peterson L, Sjögren-Jansson E, Tallheden T, Lindahl A. Articular cartilage engineering with autologous chondrocyte transplantation. A review of recent developments. J Bone Joint Surg Am 2003;85-A(Suppl 3):109-115

5 Marcacci M, Berruto M, Brocchetta D, et al. Articular cartilage engineering with Hyalograft C: 3-year clinical results. Clin Orthop Relat Res 2005;(435):96-105

6 Visna P, Pasa L, Hart R, Kocis J, Cizmár I, Adler J. [Treatment of deep chondral defects of the knee using autologous chondrocytes cultured on a support-results after one year]. Acta Chir Orthop Traumatol Cech 2003;70(06):356-362

7 Murphy CL, Polak JM. Control of human articular chondrocyte differentiation by reduced oxygen tension. J Cell Physiol 2004;199 (03):451-459

8 Brodkin KR, García AJ, Levenston ME. Chondrocyte phenotypes on different extracellular matrix monolayers. Biomaterials 2004;25 (28):5929-5938

9 da Cunha Cavalcanti FM, Doca D, Cohen M, Ferretti M. Updating on diagnosis and treatment of chondral lesion of the knee. Rev Bras Ortop 2015;47(01):12-20

10 Knutsen G, Drogset JO, Engebretsen L, et al. A randomized trial comparing autologous chondrocyte implantation with microfracture. Findings at five years. J Bone Joint Surg Am 2007;89(10): 2105-2112

11 Bentley G, Bhamra JS, Gikas PD, Skinner JA, Carrington R, Briggs TW. Repair of osteochondral defects in joints-how to achieve success. Injury 2013;44(Suppl 1):S3-S10

12 Tamez-Peña JG, Farber J, González PC, Schreyer E, Schneider E, Totterman S. Unsupervised segmentation and quantification of anatomical knee features: data from the Osteoarthritis Initiative. IEEE Trans Biomed Eng 2012;59(04):1177-1186

13 Cole BJ, Pascual-Garrido C, Grumet RC. Surgical management of articular cartilage defects in the knee. J Bone Joint Surg Am 2009; 91(07):1778-1790

14 Vaquero J, Forriol F. Knee chondral injuries: clinical treatment strategies and experimental models. Injury 2012;43(06):694-705

15 Gomoll AH, Probst C, Farr J, Cole BJ, Minas T. Use of a type I/III bilayer collagen membrane decreases reoperation rates for symptomatic hypertrophy after autologous chondrocyte implantation. Am J Sports Med 2009;37(Suppl 1):20S-23S

16 Bolliger-Stucki B, Baillod P, Mäder W, Furlan M. Biochemical properties of the fibrinogen component of a fibrin glue before and after severe dry heat treatment. J Biomed Mater Res 2000;53 (05):577-583

17 Perka C, Spitzer RS, Lindenhayn K, Sittinger M, Schultz O. Matrixmixed culture: new methodology for chondrocyte culture and preparation of cartilage transplants. J Biomed Mater Res 2000;49 (03):305-311
18 de Windt TS, Bekkers JE, Creemers LB, Dhert WJ, Saris DB. Patient profiling in cartilage regeneration: prognostic factors determining success of treatment for cartilage defects. Am J Sports Med 2009;37(Suppl 1):58S-62S

19 Saris DB, Vanlauwe J, Victor J, et al. Characterized chondrocyte implantation results in better structural repair when treating symptomatic cartilage defects of the knee in a randomized controlled trial versus microfracture. Am J Sports Med 2008;36 (02):235-246

20 Bekkers JE, Inklaar M, Saris DB. Treatment selection in articular cartilage lesions of the knee: a systematic review. Am J Sports Med 2009;37(Suppl 1):148S-155S

21 Knutsen G, Engebretsen L, Ludvigsen TC, et al. Autologous chondrocyte implantation compared with microfracture in the knee. A randomized trial. J Bone Joint Surg Am 2004;86(03):455-464

22 Micheli LJ, Moseley JB, Anderson AF, et al. Articular cartilage defects of the distal femur in children and adolescents: treatment with autologous chondrocyte implantation. J Pediatr Orthop 2006;26(04):455-460

23 Moseley JB Jr, Anderson AF, Browne JE, et al. Long-term durability of autologous chondrocyte implantation: a multicenter, observational study in US patients. Am J Sports Med 2010;38(02): 238-246

24 Roberts S, McCall IW, Darby AJ, et al. Autologous chondrocyte implantation for cartilage repair: monitoring its success by magnetic resonance imaging and histology. Arthritis Res Ther 2003;5 (01):R60-R73

25 Tins BJ, McCall IW, Takahashi T, et al. Autologous chondrocyte implantation in knee joint: MR imaging and histologic features at 1-year follow-up. Radiology 2005;234(02):501-508

26 Bartlett W, Skinner JA, Gooding CR, et al. Autologous chondrocyte implantation versus matrix-induced autologous chondrocyte implantation for osteochondral defects of the knee: a prospective, randomised study. J Bone Joint Surg Br 2005;87 (05):640-645

27 Manfredini M, Zerbinati F, Gildone A, Faccini R. Autologous chondrocyte implantation: a comparison between an open periosteal-covered and an arthroscopic matrix-guided technique. Acta Orthop Belg 2007;73(02):207-218

28 Saris DB, Vanlauwe J, Victor J, et al; TIG/ACT/01/2000\&EXT Study Group. Treatment of symptomatic cartilage defects of the knee: characterized chondrocyte implantation results in better clinical outcome at 36 months in a randomized trial compared to microfracture. Am J Sports Med 2009;37 (Suppl 1):10S-19S

29 Basad E, Ishaque B, Bachmann G, Stürz H, Steinmeyer J. Matrixinduced autologous chondrocyte implantation versus microfracture in the treatment of cartilage defects of the knee: a 2-year randomised study. Knee Surg Sports Traumatol Arthrosc 2010;18 (04):519-527

30 Vascellari A, Rebuzzi E, Schiavetti S, Coletti N. Implantation of matrix-induced autologous chondrocyte (MACI $®$ ) grafts using carbon dioxide insufflation arthroscopy. Knee Surg Sports Traumatol Arthrosc 2014;22(01):219-225 